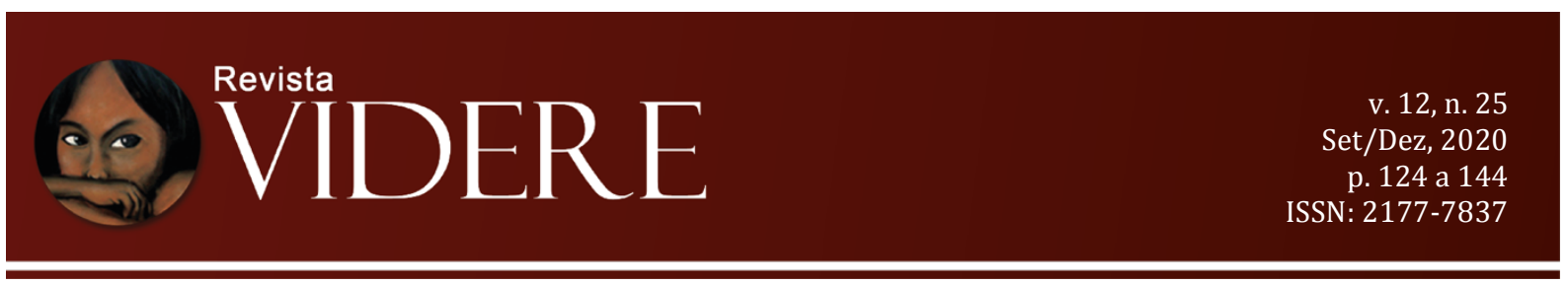

\title{
FATORES QUE LEVAM AO HIPERPRESIDENCIALISMO E A NECESSIDADE DE UMA REFORMA POLÍTICA NO ESTADO BRASILEIRO
}

\author{
FACTORS THAT LEAD TO THE HYPERPRESIDENTIALISM AND THE NEED FOR \\ POLITICAL REFORM IN THE BRAZILIAN STATE
}
FACTEURS QUI CONDUISENT À L'HYPERPRÉSIDENTIALISME ET LA NÉCESSITÉ D’UNE RÉFORME POLITIQUE DANS L'ÉTAT BRÉSILIEN

Fernando de Brito Alves Doutor em Direito pela ITE (Bauru-SP). Mestre em Ciência Jurídica pela UENP (Jacarezinho-PR) Professor da Universidade Estadual do Norte do Paraná - UENP fernandobrito@uenp.edu.br OrcidID: https://orcid.org/0000-0001-8917-4717

\begin{abstract}
Ana Flávia de Andrade Nogueira Castilho Doutoranda em Ciências Jurídicas pela UENP (Jacarezinho-PR). Bolsista CAPES/Fundação Araucária. Mestra em Direito pela UNIVEM (Marília-SP) afancmch@gmail.com OrcidID: https://orcid.org/0000-0002-6716-2018

Renan Posella Mandarino Doutorando em Direito pela UENP (Jacarezinho-PR). Bolsista CAPES/Fundação Araucária. Mestre em Direito pela UNESP (Franca-SP). remandarino@yahoo.com.br OrcidID: https://orcid.org/0000-0002-9028-2915
\end{abstract}

Resumo: O objeto da pesquisa é o hiperpresidencialismo e a sua suposta contradição com o neoconstitucionalismo latino-americano. Abordaram-se as características de ambos os institutos e as concepções da teoria da tripartição dos poderes. A investigação fundamenta os três fatores que representam a constituição dos superpoderes conferido ao presidente. A pesquisa se ampara na justificativa de ser o fortalecimento do Poder Executivo uma ameaça à democracia e uma oposição ao novo constitucionalismo, ensejando a necessidade de uma reforma política. $\mathrm{O}$ trabalho se realizou pelo método dedutivo, pela abordagem de revisão bibliográfica e com objetivos exploratórios textuais. As especulações sobre a temática levam à conclusão de que o hiperpresidencialismo está em contraposição ao neoconstitucionalismo. A democracia representativa requer uma reforma na política exercida no Brasil.

Palavras-chave: Hiperpresidencialismo. neoconstitucionalismo. democracia. reforma política. 
Abstract: The object of the research is hyperpresidentialism and it's the supposed contradiction to Latin American neoconstitutionalism. The characteristics of both institutes and the conceptions of the tripartition theory of powers were addressed. The investigation underlies the three factors that represent the constitution of the superpowers conferred to the president. The research is supported by the justification that the strengthening of the Executive Power is a threat to democracy and an opposition to the new constitutionalism, giving rise to the need for political reform. The work was carried out by the deductive method, by the bibliographic review approach and with textual exploratory objectives. Speculation on the subject leads to the conclusion that hyperpresidentialism presents a contraposition to neoconstitutionalism. Representative democracy requires reform of the policy pursued in Brazil.

Keywords: Hyperpresidentialism. neoconstitutionalism. democracy. political reform.

Résumé: L'objet de la recherche est l'hyperprésidentialisme et sa supposée contradiction avec le néoconstitutionnalisme latino-américain. Les caractéristiques des deux instituts et les conceptions de la théorie de la tripartition des pouvoirs ont été abordées. L'enquête sous-tend les trois facteurs qui représentent la constitution des superpuissances conférées au président. La recherche se fonde sur la justification selon laquelle le renforcement du pouvoir exécutif est une menace pour la démocratie et une opposition au nouveau constitutionnalisme, ce qui rend nécessaire une réforme politique. Le travail a été réalisé en utilisant la méthode déductive, l'approche de la revue bibliographique et avec des objectifs exploratoires textuels. Les spéculations sur le thème conduisent à la conclusion que l'hyperprésidentialisme est en opposition au néoconstitutionnalisme. La démocratie représentative exige une réforme de la politique exercée au Brésil.

Mots-clés: Hyperprésidentialisme. néoconstitutionnalisme. la démocratie. réforme politique.

\section{Introdução}

O hiperpresidencialismo é caracterizado pelo fortalecimento do Poder Executivo de uma nação, em que os fatores como a estrutura política, a permissão no texto constitucional e o apoio popular, favorecem a existência e coexistência deste com o neoconstitucionalismo latino americano e com a democracia representativa.

O trabalho tratará sobre a temática proposta, com intuito de estudar possíveis ameaças do Poder Executivo à democracia e ao novo constitucionalismo, quando o mesmo se encontra estruturado como hiperpresidencialismo.

Com o escopo de assentar um aporte teórico à discussão, incialmente, serão analisadas a teoria da tripartição dos poderes - Executivo, Legislativo e Judiciário - e suas atribuições. 
O hiperpresidencialismo é tratado sob suas definições, efeitos e prováveis causas de existência. Discutem-se seus possíveis danos à democracia representativa e aos objetivos do novo Constitucionalismo latino americano, sendo, essencialmente, a extrema valorização dos direitos fundamentais e da dignidade da pessoa humana, de modo a deixar a Constituição Federal no centro do sistema jurídico e político.

Ademais, avaliará sob o contexto que se pretende formar, a necessidade de uma reforma política no sistema de governo brasileiro, ressaltando o inevitável favorecimento da configuração política do país ao presidencialismo de coalizão.

A pesquisa segue o método dedutivo, com abordagem qualitativa de revisão bibliográfica e objetivos exploratórios.

\section{Os três poderes}

No direito contemporâneo brasileiro, o Poder Executivo é exercido pelo presidente da república, que é auxiliado pelos ministros de Estado (art. 76, CF/88), conferindo um sistema de governo presidencialista, que tem por objeto a administração da coisa pública. $\mathrm{O}$ Poder Legislativo é exercido pelo Congresso, que se compõe da Câmara dos Deputados e Senado Federal, o que configura o bicameralismo (art. 49, CF/88). Segundo Araújo e Nunes Junior (2007, p. 314), sua função é formular regras genéricas e abstratas. O Poder Judiciário é destinado à solução de conflitos de interesses, com fundamentos em leis, costumes e princípios gerais do direito (art. 92 e subsequentes) (SILVA, 2003, p.550). Apresentadas as funções típicas de cada poder, oportuno destacar a existência de funções atípicas de natureza administrativa, controle e política.

O princípio da separação dos poderes almeja evitar a concentração de poderes e, concomitantemente, criar uma harmonia e um equilíbrio entre eles (art. $2^{\circ}, \mathrm{CF} / 88$ ). A independência entre os poderes é disposta na Constituição Federal quando separa as atribuições de cada um deles. Porém, a Constituição pode prever exceções a está regra que, segundo Araújo e Nunes Junior (2007, p. 316), em nada desfigura a divisão orgânica de poder adotada pela $\mathrm{CF} / 88$, de modo que a interferência de um poder sobre o outro somente será admissível quando visar equilíbrio no relacionamento entre eles ou garantir o pleno exercício das funções próprias.

Inviável a manutenção de poderes harmônicos, independentes e autônomos com uma estrutura rígida de funções, pois as exigências de ordem prática, nos dias atuais, pedem um afrouxamento entre as fronteiras dos poderes e suas funções (ARAÚJO; NUNES Jr., 2007, p. 
336-337). Cada poder exerce de forma subsidiária a função que, originalmente, seria de outro.

Neste contexto teórico, floresce o fortalecimento excessivo de um dos poderes - o Poder Executivo -, o que torna apropriado compreender a complexidade desse movimento no processo democrático e a sua relação com o hiperpresidencialismo.

\section{O fortalecimento do Poder Executivo}

O processo de redemocratização, iniciado no final da década de 1970, foi bastante complexo e precedido de um intenso debate sobre o modelo institucional que deveria ser adotado após a refundação da República com uma nova Constituição. Diversos autores acreditavam que o presidencialismo, modelo institucional adotado no período antecedente, não deveria ser retomado, diante da malfadada experiência resultante no golpe militar. É possível constatar, ao analisar os anuários da constituinte de 1987-1988, que a forma presidencialista de governo e as leis eleitorais foram intensamente debatidas e prefiguraram o tema de várias propostas de reforma institucional.

Acreditavam os constituintes, mas também uma parte da sociedade civil, que o presidencialismo conduz a conflitos institucionais insolúveis na mesma medida em que o número excessivo de partidos, associado à relativa facilidade para criação de novos, também cooperaria com isso. Ao fim, consolidou-se o "pior dos mundos: a explosiva combinação entre presidencialismo e um sistema pluripartidário baixamente institucionalizado" (LIMONGI; FIGUEIREDO, 1998, p. 91).

O resultado foi que a democracia brasileira refundada dependia da realização de um exercício de complexa engenharia institucional, que resultou em uma espécie de presidencialismo de coalização.

A principal evidencia disso é o fato de que os poderes do Presidente da República, embora a Constituição Federal the tenha reservado competências exclusivas ou próprias, são sindicáveis pelo Poder Legislativo e, também, pelo Poder Judiciário.

Isso faz com que as decisões sobre dissensos morais complexos, para que sejam de fato resolutivas, devam ser tomadas em um relativo contexto de diálogo institucional entre os poderes, sobretudo, entre o Executivo e o Legislativo. Esse diálogo pode conduzir a relações pouco republicanas e de codependência que obriguem a barganhas para aprovação de pautas de intensa repercussão social.

A Nova República, ou Sexta República brasileira, é caracterizada pelo progressivo fortalecimento dos poderes do chefe do executivo. O parlamento torna-se dependente do 
Presidente da República para: a distribuição de cargos e posições no governo; a liberação de recursos indicados em emendas parlamentares; a implementação de planos de ação ou programas que beneficiassem sua base de apoio, sempre em troca da governabilidade.

O fortalecimento do poder do Chefe de Estado está conexo com três fatores. Primeiro, com a expressa previsão de muitas competências discricionárias atribuídas a ele na Constituição do Estado; segundo, pela configuração política do Estado ser favorável e, terceiro, pelo apoio popular que experimenta a figura do executivo (BOLONHAS et al, 2015, p. 121-122).

No nosso caso específico, a Constituição Brasileira de 1988 estabelece como faculdades discricionárias, que foram amplamente utilizadas pelos presidentes da república ao longo dos últimos trinta anos: a expedição de decretos (art. 84, IV, CF), medidas provisórias (art. 62, CF) e a iniciativa para apresentar propostas de emendas à Constituição (art. 60, CF).

Da mesma forma, permite-se ao Presidente a escolha de ministros de Estados, indicação ao Supremo Tribunal Federal, Procuradoria Geral da República, Advocacia Geral da União e Presidente dos Bancos Públicos, das Agências Reguladoras e outros órgãos, desde que haja previsão legal (art. 84 a XVI, CF).

Em outros países da América Latina, com mudanças constitucionais recentes, nota-se o mesmo movimento de fortalecimento do Poder Executivo. São nações onde a forma de governo é o presidencialismo e sustentada por uma suposta tripartição dos poderes equilibrados e harmônicos.

As atribuições estabelecidas ao Poder Executivo na Constituição Peruana de 1993 se assemelham com a do Brasil. Em seu artigo 118, item 7, autoriza o presidente a ditar ao Congresso as reformas necessárias e convenientes ao presidente ${ }^{1}$. É consentida a expedição de decretos de urgências com força de lei em matéria econômica e financeira ${ }^{2}$.

De acordo com Bolonhas e outros (2010, p.124), dentre as constituições da América Latina, a Carta Maior que mais confere poder ao Executivo é a do Equador.

A Constituição do Equador (2008) permite veto total ou parcial aos projetos de leis ${ }^{3}$,

\footnotetext{
${ }^{1}$ Artigo 118. Item 7. Dirigir mensajes al Congresoencualquier época y obligatoriamente, en forma personal y por escrito, al instalarse la primera legislatura ordinaria anual. Los mensajesanualescontienen la exposicióndetallada de la situación de la República y lasmejoras y reformas que el Presidente juzguenecesarias y convenientes para suconsideración por elCongreso. Los mensajesdel Presidente de la República, salvo elprimero de ellos, sonaprobados por elConsejo de Ministros.

2 Artigo 118. Item 19. Dictar medidas extraordinarias, mediante decretos de urgenciaconfuerza de ley, enmateria económica y financiera, cuandoasílorequiereelinterés nacional y con cargo de dar cuenta al Congreso. El Congresopuede modificar o derogarlos referidos decretos de urgencia.

3 Art. 139.- Si la objeción de la Presidenta o Presidente de la República se fundamenta en la inconstitucionalidad total o parcial delproyecto, requerirádictamen de la Corte Constitucional, que lo emitirá dentro delplazo de treintadías. Si eldictamen confirmara la inconstitucionalidad total delproyecto, éste será 
edição de decretos e medidas provisórias ${ }^{4}$ e, o que mais chama a atenção, são as competências exclusivas do presidente para iniciar um processo legislativo em matérias tributárias, orçamentárias, monetárias, cambiária, creditícias, entre outras (BOLONHAS et al, 2010, p. 124).

Ao contrário do proposto, o hiperpresidencialimo poderá existir sem o favorecimento da Constituição do Estado. O Chile e a Argentina sustentam o fortalecimento do Poder Executivo pela coalizão partidária. O México vivenciou o Presidencialismo hegemônico, isto é, uma ausência de oposição e concorrência partidária (BOLONHAS, et al, 2010, p. 127-129).

Ao que se refere à configuração política favorável ao hiperpresidencialismo, o Brasil se coloca em uma posição escandalosamente positiva a isto. Tem-se uma política singular quanto às suas características que se situa em multipartidarismo, representação proporcional, federalismo, bicameralismo e presidencialismo (ABRANCHES, 1988).

O multipartidarismo consiste em uma exagerada formação de partidos políticos. São mais de trinta partidos políticos no Brasil. Isso se explica pela liberdade dada pela Constituição Federal em seu artigo 17, que estabelece ser livre a criação, fusão, incorporação e extinção de partidos políticos, resguardados a soberania nacional, o regime democrático, o pluripartidarismo e os direitos fundamentais da pessoa humana.

Um sistema multipartidário de coalizão pode trazer consequências positivas e negativas. Num raciocínio lógico, analisa-se que há maiores dificuldades na concentração do poder político nas mãos dos grandes partidos aliados, ou seja, uma coalizão partidária que salienta a formação de vários grupos heterogêneos nas ideologias culmina com a democracia. Por outro lado, facilmente, pensa-se em proliferação da corrupção.

Uma posição contrária ao multipartidarismo brasileiro está na ausência de apoio político ao Poder Executivo quando este se encontra em baixa popularidade por motivos de insatisfação do povo, adversidades no Congresso e de seus próprios membros do partido, dificultando a posição do presidente no que se refere à implementação de medidas coerentes para a gestão política. Tal situação pode ser uma indução à instabilidade democrática.

Scott Mainwaring (1993, p. 2), inclusive, comenta as dificuldades de manter um presidencialismo multipartidário quando o poder executivo está em minoria. $\mathrm{O}$ autor cita o Brasil e a sua instabilidade democrática em diversos momentos, antes e depois da ditadura militar:

archivado, y si esta fuera parcial, la Asamblea Nacional realizará lasenmiendasnecesarias para que elproyectopase a la sanción de la Presidenta o Presidente de la República. Si la Corte Constitucional dictamina que no hayinconstitucionalidad, la Asamblea Nacional lo promulgará y ordenará supublicación.

${ }^{4}$ 11. Participar con iniciativa legislativa enelproceso de formación de lasleyes. 
Os presidentes enfrentam essa situação valendo-se de uma variedade de práticas. Com frequência tentaram passar por cima dos partidos e do Congresso, de forma que seus programas mais importantes não fossem ameaçados pelo imobilismo e pela inércia do Congresso ou pelos objetivos clientelistas dos políticos. Percebendo que sua base de sustentação em qualquer partido específico - incluindo o seu próprio - nunca é inteiramente confiável, os presidentes muitas vezes tentam constituir coalizões multipartidárias mediante a distribuição de patronagem. Vários presidentes - Vargas, Quadros e Goulart - tentaram mobilizar as massas como um meio para compensar a falta de apoio institucional, mas agindo assim enfraqueceram ainda mais as instituições políticas. Mesmo armados com essa panóplia de recursos, os chefes do executivo tiveram dificuldade em governar como presidentes minoritários em um sistema partidário fragmentado e dominado por partidos gelatinosos. Esse sistema institucional conduziu quase todos os presidentes democraticamente eleitos ao fracasso. Levou um deles (Vargas) ao suicídio, outro (Quadros) à renúncia apenas alguns meses depois de uma arrasadora vitória eleitoral, incentivou outro (Goulart) a recorrer a ações erráticas que contribuíram para o colapso da democracia e tornou possível a um presidente inepto e impopular (Sarney) completar seu mandato a despeito de não dispor de condições mínimas para enfrentar uma crise severa.

Mainwaring (1993) enfatiza que um presidente, com frequência, encontra dificuldade para encontrar sustentação no Congresso Nacional devido à combinação entre um sistema partidário heterogêneo com partidos indisciplinados. Isso acarreta conflitos e impasses entre o executivo e o legislativo, que não se apoiam em períodos difíceis.

Conforme afirmado anteriormente, a instabilidade gerada na democracia pelo multipartidarismo não foi solucionada pela Constituição de 1988. Embora, há quem defenda o modelo pluripartidário adotado pela CF/88, como é o caso de Valeriano Costa (2012, p.5), ao constatar que o multipartidarismo corrobora com os avanços em termos sociais e econômicos e aperfeiçoa os sistemas de controle democrático.

Quanto ao terceiro elemento que favorece o hiperpresidencialimo - o apoio popular sua existência condiciona-se por três fatores, segundo as análises de Bolonha e outros (2010, p. 131): a estabilidade e prosperidade econômica; o aumento dos direitos sociais; a maior participação popular na gestão governamental, como referendos e consultas públicas; a formação de conselhos de políticas públicas (em geral controlados pelo chefe do executivo); a realização de audiências públicas para discussão do orçamento público e outros temas de relevância pública; a formação de uma militância fiel em torno de personalidades altamente carismáticas.

Esses elementos favorecem o estabelecimento de um regime autocentrado na pessoa do Presidente da República e na sua capacidade de articulação com os demais poderes para o 
estabelecimento de consensos.

Para ilustrar a popularidade dos presidentes da América Latina, Bolonha e outros (2010) elaborou o seguinte gráfico (Figura 1):

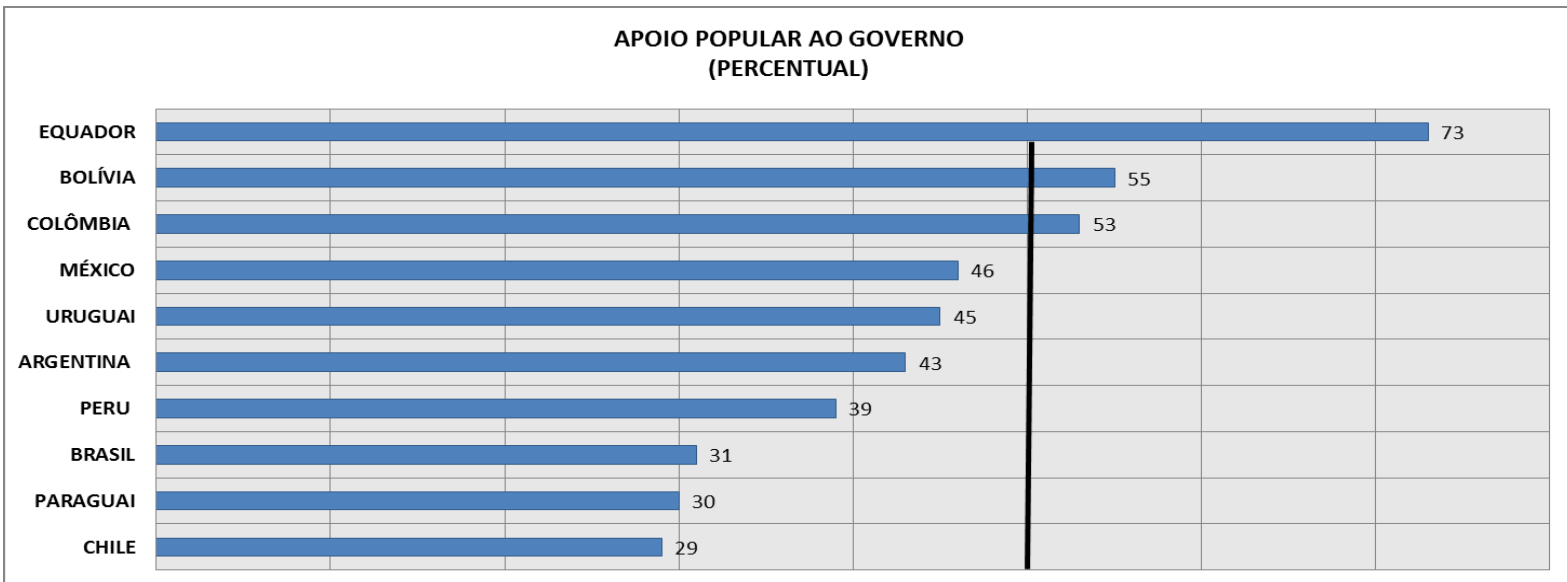

Figura 1 - Apoio popular ao governo na América Latina. Fonte: Bolonha et al (2010, p. 131)

Atualizando os dados estatísticos da figura acima, de acordo com os institutos de estatística de cada país, verifica-se que entre 2010 e 2016 ocorreram mudanças significativas no quadro de popularidade (Figura 2):

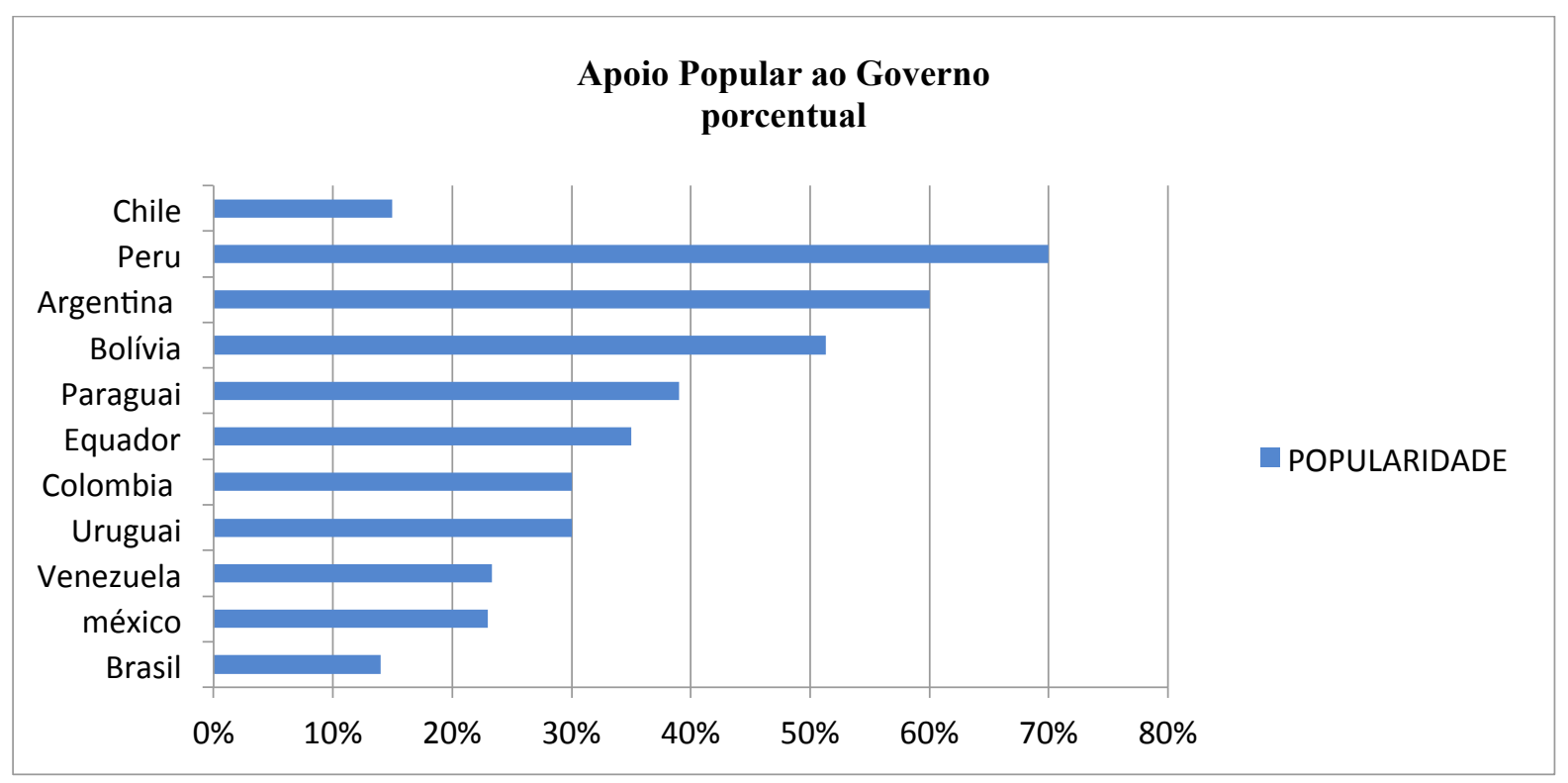

Figura 2 - Apoio popular ao governo da América Latina. Fonte: Dados levantados por Charleaux e Iandoli (2016) em reportagem para o jornal eletrônico NEXO.

Charleaux e Iandoli (2016) apontam que a popularidade dos presidentes latinos americanos sofreu alterações porcentuais consideráveis. O Brasil é um exemplo de ausência 
de apoio popular ao governo, decorrente da incapacidade de negociação com o Parlamento. $\mathrm{Na}$ Nova República, essa incapacidade de comunicação entre os poderes implicou em discussão frequente de "pautas bomba" no Congresso Nacional, o que agravava a crise política e, também, a crise econômica decorrente da necessidade de ajustes, das políticas de subvenção, da valorização artificial do dólar no exterior (que forçava o aumento da taxa de juros) e da adoção da agenda FIESP, que fez com que o governo concedesse estímulos às indústrias, que não resultaram em investimento, mas no aumento e na otimização dos lucros.

Em 2010, conforme demonstra o gráfico anterior, a posição estatística era o sétimo lugar, em 2015 encontra-se em décimo primeiro, haja vista, acrescentou-se a Venezuela nesta coleta de dados.

O governo equatoriano ocupava o primeiro lugar no apoio popular, por motivos políticos e econômicos passa para a sexta posição. O Equador, além da crise econômica, sofreu alguns outros abalos com a regulamentação da liberdade de imprensa que ficou estabelecida após a Lei das Comunicações criada no governo de Rafael Correia ${ }^{5}$ (PILLARES, 2015).

Essa mudança estatística quanto à popularidade pode objetar a afirmação de Bolonha e outros $(2015$, p. 132) sobre ser o Equador o único país a se destacar nos três aspectos avaliados que mais fortalece o Poder Executivo. Porém, mesmo com a popularidade de Correia baixa, seus superpoderes ainda se destacavam pelo modelo político favorável e texto constitucional compatível com seus feitos, ou seja, ele exercia com relativa liberdade todos os poderes que a Constituição do Equador lhe conferia.

De acordo com os mesmos autores (2015), em uma ordem crescente, os países que mais demonstram a presença do hiperpresidencialismo são: Equador, Brasil, México, Argentina, Chile, Bolívia, Colômbia, Peru, Uruguai e Paraguai. Essas posições estatísticas estão relacionadas com o manejo das prerrogativas constitucionais do Poder Executivo.

Importante destacar a presença do hiperpresidencialismo em outro país da América Latina: a Venezuela. Esta combina práticas eleitorais fracamente institucionalizadas, embora relativamente livres, com características autoritárias claras, com complexas dinâmicas de centralização do poder em direção à figura do Presidente.

Penfold (2010, p. 39) conclui que a Venezuela possui uma democracia exclusivamente eleitoral, subjugada pelas potências presidenciais. Não é uma democracia constitucional e cidadã, restringindo a participação popular ao voto. Inexiste diálogo entre os

\footnotetext{
${ }^{5}$ Since 2013 Ecuador has a Communications Law that created a superintendency that controls and regulates the media, and answers directly to the executive branch. The New York Times. 
Poderes Legislativo e Judiciário, arrefecendo a participação dos referidos poderes nas decisões políticas.

Ademais, o Presidente possui um grande controle no Conselho Nacional Eleitoral, órgãos este responsável por gerir as eleições, criando assimetrias significativas que aumentam as desigualdades na competição política. Esse controle permite ao partido no poder excluir potenciais candidatos da oposição da arena eleitoral. Assim, a democracia venezuelana se limita à dimensão eleitoral, a qual é facilmente controlável pelo Presidente.

O hiperpresidencialismo pode afrontar a democracia. Os poderes excessivos concedidos ao Poder Executivo ensejam consequências negativas, uma vez que o equilíbrio entre os três poderes pode estar ameaçado pela cooptação do legislativo pelo Poder Executivo. A reflexão pode ser mais abrangente por meio das seguintes questões: há mesmo uma "invasão" do Poder Legislativo pelo Poder Executivo? Não se trata de uma permissão constitucional a fim de atender os anseios da sociedade diante da morosidade do legislativo? O hiperpresidencialismo está em oposição ao neoconstitucionalismo?

\section{Neoconstitucionalismo, democracia representativa e o hiperpresidencialismo}

O neoconstitucionalismo, intitulado pela doutrina de constitucionalismo pósmoderno ou pós-positivista, tem seu marco inicial no século XXI e almeja não apenas atrelar o constitucionalismo a uma limitação do poder político, mas, sobretudo, buscar a uma maior eficácia da Constituição.

Tradicionalmente, os direitos fundamentais podem ser delimitados de acordo com dois critérios distintos: um material e outro formal. O critério formal é o consubstanciado pelo Título II da Constituição Federal de 1988, "Dos direitos e garantias fundamentais"; o critério material restou consignado no artigo $5^{\circ}$., $\S 2^{\circ}$, da Constituição Federal.

O rol trazido pela Constituição traduz direitos fundamentais do ponto de vista formal, por relacionados entre os direitos fundamentais, mas não exclui outros “decorrente do regime e dos princípios", especialmente, o da dignidade da pessoa humana, que atribui unidade valorativa ao sistema dos direitos fundamentais (NUNES JÚNIOR, 2009, p. 30-32).

Os direitos fundamentais consubstanciam três valores essenciais: liberdade, democracia política e democracia econômica e social (CANOTILHO; MOREIRA, 1991, p. 106.). Sustentamos, contudo, que os valores são apenas dois: liberdade e democracia, pois os direitos fundamentais e a democracia possuem gênese distinta e já puderam ser considerados 
inimigos.

Em tempos contemporâneos, todavia, com a incorporação da democracia ao rol de direitos fundamentais, essa relação tensa se alterou drasticamente: a democracia, além de direito fundamental, passou a ser a própria condição de sua fundamentalidade. Os direitos fundamentais, por isso, traduzem dois valores, que estão em profunda tensão: liberdade e democracia, com este último cambiável por igualdade, sem qualquer perda de conteúdo semântico axiológico.

Vidal Serrano apresenta como características dos direitos fundamentais: (1) a historicidade, (2) a universalidade, (3) a autogeneratividade, (4) a irrenunciabilidade, (5) a limitabilidade e (6) a possibilidade de concorrência (NUNES JÚNIOR, 2009, p. 30-42).

Apesar de seu reconhecimento pela doutrina, apropriada algumas considerações a mencionada classificação. A primeira consiste em que a tese da historicidade dos direitos fundamentais tem como pressuposto uma concepção positiva da história, como ela fosse linear e sempre conduzisse a uma "conscientização crescente" decorrente e concomitantes à “evolução das relações sociais" (NUNES JÚNIOR, 2009, p. 36), o que pode significar ao mesmo tempo um "pensar o já pensado" de forma hiperbólica para que apresente facetas ou dimensões supostamente novas ou ainda supor que não haveriam digressões ou rupturas ${ }^{6}$.

A segunda característica aponta para a universalidade suposta dos direitos fundamentais, haja vista, que são destinados ao ser humano enquanto gênero. Há que se distinguir titularidade de fruição: a titularidade é universal, todavia a fruição de boa parte deles pode parecer escandalosamente restritiva.

A terceira característica sinaliza a existência de uma reserva de justiça (que é histórica, contingente e não arbitrária - em evidente oposição a qualquer espécie de jusnaturalismo racionalista); perguntamos, qual distinção existe entre a autogeneratividade e a historicidade dos direitos fundamentais? Da mesma forma, a limitabilidade e a possibilidade de concorrência não podem ser consideradas características exclusivas dos direitos fundamentais.

Dito isso, é forçoso concluir que o sistema dos direitos fundamentais congrega realidades tão diversas que não é possível encontrar rol extenso de características comuns.

De acordo com Vidal Serrano, os direitos sociais que nascem de aspirações de

\footnotetext{
${ }^{6} \mathrm{O}$ tema da ruptura da tradição é, portanto, modulado em duas chaves distintas. Por um lado, remete aos dilemas da compreensão e do pensamento no presente, que não mais podem fiar-se nos conceitos da tradição e ao risco da própria perda e esquecimento do passado enquanto estoque heterogêneo de experiências e conceitos. Por outro lado, entretanto, a ruptura da tradição constitui a condição para sua própria releitura crítica e para a recuperação dos conteúdos políticos não veiculados. (DUARTE, A. O pensamento à sombra da ruptura. São Paulo: Paz e Terra, 2000, p. 153).
} 
alforria da classe operária, surgem no contexto estruturalmente crítico do capitalismo embrionário. Direitos sociais passam a prefigurar diversas Constituições europeias e americanas, além das declarações internacionais de direitos (NUNES JÚNIOR, 2009, p. 4956).

Os direitos sociais e as liberdades individuais são as categorias de direitos mais concretizados pelo neoconstitucionalismo, especialmente, porque esses direitos eram considerados, em sua grande maioria, positivados por normas de caráter programático.

Os direitos sociais possuem algumas características básicas: são direitos subjetivos, que decorrem da atividade normativo-regulamentadora do Estado, e se constituem em instrumentos assecuratórios (NUNES JÚNIOR, 2009, p. 68-69).

Quanto às técnicas de positivação e respectivos regimes jurídicos dos direitos sociais, Vidal Serrano (op. cit. p. 97-167) pondera que várias foram as técnicas adotadas pelo poder constituinte: (1) positivação por meio de normas programáticas que se limitam a apontar diretrizes, tarefas ou finalidades a serem atingidas pelo Poder Público, como o pleno emprego, nesse caso só poderia haver lesão por parte do Estado do dever geral de proteção. Essas normas podem (1.1) decorrer dos princípios informadores do Estado Democrático Social de Direito, entre os quais se destacam os consubstanciados pelos artigos $1^{\circ}$., $3^{\circ}$., $5^{\circ}$. (caput), bem como pelo inciso III e XXIII, art. $6^{\circ}$., do art $7^{\circ}$. ao art.11, art. 34, VII, “e”, art. 35, III, art. 133, art. $145, \S 1^{\circ}$., art. 170, e do art. 193 ao art 232, todos da Constituição Federal. As principais normas são derivadas dos princípios da (1.2) dignidade da pessoa humana, (1.3) justiça social e (1.4) proibição do retrocesso, por exemplo; (2) positivação por meio da atribuição de direitos públicos subjetivos, por exemplo, o artigo 205 combinado com o artigo 208 da Constituição Federal; (3) positivação por meio de normas consubstanciadoras de garantias institucionais, como ocorre com o inciso III, $\S 4^{\circ}$. do art. 182 , o art. 184 , o $\S 2^{\circ}$. do artigo 198, o $\S 1^{\circ}$. do artigo 199, o art. 212, todos da Constituição Federal, para citar apenas algumas; (4) positivação por meio de cláusulas limitativas do poder econômico como a contida no artigo $9^{\circ}$. da Constituição Federal; (5) positivação por meio de normas de conformação do perfil social dos institutos fundantes da ordem econômica capitalista, como o art. 5'. XXIII, art. 170, III, art. 184 a art. 186. Diversos direitos sociais que antes eram considerados meros programas, como o direito de acesso à saúde, passam a ser ativamente reconhecidos pelos tribunais.

Com relação às liberdades individuais, no contexto do neoconstitucionalismo, são reconhecidos diretos relacionados à igualdade de gênero, de raça, liberdade sexual, e tantos outros, principalmente pelo exercício da jurisdição constitucional. 
Além desses dois fenômenos, os Tribunais passaram a atuar também como legisladores positivos, na hipótese específica de omissão inconstitucional, tendo em vista que a $\mathrm{CF} / 88$ autoriza a troca de sujeitos legitimados para o estabelecimento de normas gerais nessa hipótese.

Em suma, o neoconstitucionalismo representou uma profunda ruptura com a cultura constitucional antecedente, ao restabelecer a força normativa das Constituições, resgatar a dignidade da legislação e, ao mesmo tempo, gerar o empoderamento do Poder Judiciário. O novo constitucionalismo se caracteriza pela incorporação explícita de valores e opções políticas nos textos constitucionais, acima de tudo no que diz respeito à promoção da dignidade humana e dos direitos fundamentais (BARCELLOS, 2007, p. 4).

O neoconstitucionalismo reconhece a complexidade da sociedade e assimila o pluralismo jurídico. Apoiam-se no discurso de que as Constituições exercem um papel relevante na modificação da realidade, pois se caracterizam pela existência de metarregras (direito sobre direito), isto é, são dotadas de normas superiores (supremacia da Constituição), justamente para vincular os poderes públicos, com o escopo de transformar o direito na direção da realização dos direitos fundamentais.

O neoconstitucionalismo está voltado à realização do Estado Democrático de Direito, por intermédio da efetivação dos direitos fundamentais. Aposta no caráter transformador das Constituições modernas, no sentido de orientar as necessárias mudanças sociais (CAMBI, 2020, p. 27-28). É, portanto, uma visão instrumental do direito, com aspirações reformistas da sociedade.

No entanto, ainda há a concepção do neoconstitucionalismo latino- americano que recebe a denominação de "novo constitucionalismo latino-americano". Segundo Fangoski e Braun (2012, p. 4), o novo constitucionalismo tem como preocupação a legitimidade popular, a construção democrática e participativa, comprometimento com as demandas sociais que impulsionaram os novos textos constitucionais e a redimensão jurídica em favor das necessidades fundamentais. Tais fatores fizeram surgir o movimento denominado "novo constitucionalismo latino-americano".

As Constituições da Bolívia, Colômbia, Equador, Venezuela são expoentes do novo constitucionalismo. $\mathrm{O}$ aspecto marcante nelas é o protagonismo popular antes e depois do “processo constituinte, com base na mobilização popular para a formação do poder constituinte permanente, o que o diferencia do constitucionalismo tradicional no qual o poder constituído se distancia da participação do povo" (FANGOSKI; BRAUN, 2012, p. 4).

Para Bolonhas e outros (2010, p 117), a figura do Poder Executivo é lançada para um 
segundo plano por este modelo de constitucionalização ou de hermenêutica constitucional. O Hiperpresidencialismo é reconhecido como um obstáculo aos objetivos do novo constitucionalismo, que pretende em grandes reformas constitucionais ou a aprovação de novas constituições, quando necessário.

Quanto à ideia de ofensas à democracia atualmente estabelecida na sociedade contemporânea, insta observar que o modelo de democracia representativa não necessariamente sofre abalo com o fortalecimento do Poder Executivo.

A CF/88 estabelece, em seu artigo $1^{\circ}$, parágrafo único, a concepção da democracia representativa, ao dispor que todo o poder emana do povo, o qual o exerce por meio de representantes eleitos ou diretamente. No artigo 14, a Constituição Federal integra a democracia participativa no capítulo destinado aos direitos políticos ao disciplinar que a soberania popular será exercida pelo voto direto e secreto, com valor igual para todos, e, nos termos da lei, mediante plebiscito, referendo e iniciativa popular.

De acordo com o estudado, pode-se compreender que o fortalecimento de um poder ou de outro não sufoca as funções típicas de nenhum deles. Bolonha e outros (2010, p. 137) em semelhante estudo não fizeram conclusões sobre a existência do hiperpresidencialismo e seus efeitos. Os autores afirmam que não era possível concluir que as mudanças Constitucionais na América Latina ocorreram em função do fortalecimento do poder Executivo, e nem o contrário poderia ser uma hipótese confirmada.

Inegável que as Constituições na América Latina conferem ao presidente um poder extra de suas funções; porém, não se difunde nesta permissão o autoritarismo, supressão de direitos fundamentais ou, ainda, afirmar que exista a supressão dos objetivos do neoconstitucionalismo elencados neste trabalho e ofensas à democracia representativa.

Araújo e Nunes Junior (2007, p. 316) lecionam que a interferência de um poder em outro em nada desfigura a divisão orgânica de poder adotada pela $\mathrm{CF} / 88$, pois a interferência de um poder sobre o outro é admissível quando visa harmonia no relacionamento entre eles ou garante o pleno exercício das funções próprias. Isso permite asseverar que a democracia representativa é formalmente respeitada nos moldes da Constituição Federal.

Nesta concepção, há autores que acreditam na existência do hiperpresidencialismo, porém enfatizam que o mesmo foi mitigado pelo controle de constitucionalidade, como aduz Pulido: 
que foi concebido, em princípio, como um controle jurídico objetivo e de caráter negativo, fundado em técnicas interpretativas elaboradas pela metodologia constitucional e uma abordagem dogmática dos direitos fundamentais, transformou-se em um controle com claras tendências políticas, no qual já não se discute acerca da distinção entre a lei e a Constituição, senão sobre a conveniência ou a coerência de certas políticas públicas. Nesse mesmo sentido, a Corte Constitucional atribuiu a si um controle, não só formal, senão também material dos atos de reforma da Constituição, quando estes tenham sido propostos pelo Governo e levados a cabo pelo Congresso, este último cumprindo papel de constituinte secundário. (PULIDO, 2012, p. 8)

Segundo a autora, o controle de constitucionalidade evita que o presidente trace seus planos de governo e molde a constituição do país de acordo com seus interesses, como tentou fazer o presidente colombiano, Álvaro Vélez. Ele intentou um pleito ao Congresso ${ }^{7}$ para que fosse aprovada uma emenda no sentido de viabilizar um referendo para votar pela reeleição consecutiva de dois mandatos, mas o referendo foi declarado inconstitucional pela Corte Constitucional (COLOMBIA, 2010).

Pulido (2012, p. 8) cita outro exemplo de abuso do Poder Executivo, quando aduz sobre os governos mexicanos na era da hegemonia do Partido Revolucionário Institucional $\mathrm{PRI}^{8}$, no qual cada Presidente reformava a Constituição durante seu mandato para incorporar na máxima norma do ordenamento jurídico seus programas de governo. Havia uma perversão do constitucionalismo, extrapolando os limites de governo e, sem dúvida, ferindo a democracia representativa à medida que exercia havia autoritarismo nos atos do executivo.

\section{Reforma política}

Antes do enfrentamento da questão da crise da democracia representativa é necessário esboçar as características preliminares da nossa compreensão de crise, tendo em vista que se trata de conceito polissêmico. "Crise" é um signo onipresente em quase todos os tipos de narrativas e tem sido mobilizado como categoria definidora do contemporâneo (ROITMAN, online).

\footnotetext{
${ }^{7}$ La Sentencia C-141 de 2010 (M.P. Humberto Sierra Porto), mediante la cual la Sala Plena de la Corte Constitucional decidió Declarar INEXEQUIBLE ensu totalidad la Ley 1354 de 2009 "Por medio de la cual se convoca a un referendo constitucional y se somete a consideración Del pueblo um proyecto de reforma constitucional”, al considerar que, una segunda reelección presidencial sustituye ejes estructurales de la Constitución Política y, por lo tanto, la Ley 1354 de 2009 que busca hacerposible una reforma constitucional que la instituya vulnera la Carta y debe ser declarada inconstitucional.

${ }^{8}$ O Partido Revolucionário Institucional (PRI) é um dos principais partidos políticos do México que teve o poder hegemônico sobre este país entre 1929 até 2000. Todos os presidentes do México foram deste partido, até que foi derrotado nas eleições do ano de 2000 pelo candidato do Partido da Ação Nacional, Vicente Fox Quesada. 
Michaela Richter e Reinhart Koselleck (2006, p. 357-400) consideram que o conceito de crítica e crise são cognatos. Ao se falar de crise, o discurso oculto encerra um juízo moral e comparativo entre o passado e o futuro, de modo que somos levados a nos perguntar sobre o que deu errado. Todavia, sublinha-se a compreensão de que não há "crise" e "não-crise", a crise é no fim uma "observação lógica que gera significado em um sistema auto-referencial, ou um não-lugar a partir do qual a significar contingência e paradoxo" (ROITMAN, online).

Ao retomar as reflexões de Koselleck e Richter, fortemente influenciadas por Carl Schimitt (2007), adequado repolitizar as discussões contemporâneas sobre democracia representativa, resgatando que o conflito é da natureza da vida política, de modo que não é possível a ocorrência do político, se crise ou crítica.

As criticas à democracia representativa não são recentes. Philippe Lauvaux (op. cit., p. 84-85) afirma que elas já ocorrem de forma bastante veemente nos textos de Rousseau, Carré de Malberg e de Hans Kelsen, por exemplo.

Não resta dúvida, contudo, que atualmente existe o déficit de representação tem se aprofundado. Os vínculos de confiança são difíceis de serem estabelecidos, resultando no desinteresse do povo pelo exercício da cidadania e pela participação política (PELLENZ; BASTIANI, 2015, p. 102).

Nota-se que uma reforma política profunda pode ser um caminho de fortalecimento da democracia e do Estado Democrático de Direito. O sistema político precisa estimular a participação direta dos cidadãos nos processos decisórios e na efetivação das políticas públicas de um Estado. O povo encontra-se afastado do Estado, vivenciando uma Democracia limitada e participando muito timidamente das decisões políticas do país (PELLENZ; BASTIANI, 2015, p. 104).

Ricardo Pinha Alonso (2017, p. 139) destaca esse cenário de afastamento popular do "jogo" democrático:

Está instaurada no Brasil não apenas uma crise de representatividade como também uma crise funcional no legislativo onde deveria estar concentrada a representação popular. Eleitores estão distantes dos eleitos e já não vislumbram nessas figuras, qualquer vínculo de representação. Os mandatários do poder político, por sua vez, não se veem inseridos numa verdadeira relação de representação e, ao contrário, os fatos demonstram que passaram a representar interesses pessoais ou meramente corporativos de grupos econômicos, com ações ilegais, inclusive.

Parcos são os instrumentos a permitir o exercício da democracia pelo titular no 
sistema brasileiro. Inexiste iniciativa popular para apresentação de propostas de emendas constitucionais. Não há iniciativa popular para impugnação, via controle concentrado, das leis, em tese, inconstitucionais. Não há possibilidade de revogação de mandato eletivo em qualquer instância ou poder. O pluripartidarismo impede a governabilidade e a implantação da estabilização de programas de governo consagrados e escolhidos nas eleições presidenciais, provocando um Presidencialismo de Coalizão que não costuma produzir resultados satisfatórios (ALONSO, 2017, p. 139).

A estrutura do poder político dos países latino-americanos se fundamentam na "democracia delegativa", consubstanciada num excessivo verticalismo do sistema presidencialista com os vínculos políticos. Existe a centralização da crença de que o presidente, o "salvador da pátria", é competente para absolver todas as expectativas sociais. Uma espécie de "representação exclusiva da soberania popular" (LÓPEZ; CUENCA, 2014, p. 16).

As críticas atribuídas ao presidencialismo latino-americano se mostram mais evidente do que o presidencialismo americano: instabilidade econômica constante da região e, por conseguinte, a necessidade de tomada rápida de decisões em matéria de saúde, educação, política social e política econômica, que não é facilitada pelo imobilismo do regime presidencial (BASTOS, 2019, p. 207).

Tais problemas apontados na democracia representativa levam a refletir acerca da possibilidade de implantação de um modelo político mais participativo, que provoque a coexistência dos interesses políticos em consonância com os interesses sociais.

\section{Conclusão}

A partir do objetivo da pesquisa de demonstrar os efeitos do hiperpresidencialismo na atualidade e apresentar as especulações sobre o questionamento de ser incompatíveis hiperpresidencialismo, neoconstitucionalismo e democracia representativa, foi possível traçar algumas considerações diante da visão doutrinária e das interpretações dedutivas que foram elencadas a fim de responder as hipóteses previamente apresentadas.

A primeira discussão se pautou no desequilíbrio dos três poderes ao reconhecer a existência do fortalecimento do Poder Executivo. De acordo com os autores estudados, pode não haver um rompimento da harmonia entre eles, visto que se compreende que não é viável uma estrutura rígida de funções, pois as exigências de ordem prática, nos dias atuais, pedem um afrouxamento entre as fronteiras dos poderes e suas funções, de maneira que cada poder 
exerce de forma subsidiária o que originalmente seria de outro.

Para quem visualiza uma distorção da organização dos três poderes, no qual o Poder Executivo exerce funções típicas do Poder Legislativo, traz exemplos de países que os governantes ultrapassam os limites constitucionais e passam a impor seus interesses de forma autoritária ou com manobras desonestas, como foi o caso dos exemplos citados da Colômbia e do México.

Quanto ao fortalecimento do Poder Executivo, tal movimento se dá por meio de três fatores observados nas pesquisas ao longo das instituições ou reformas das novas Constituições na América Latina. O primeiro fator consiste na expressa previsão legal de competências atribuídas ao Presidente (Chefe do Executivo) na Constituição do País. O segundo fator se expressa na configuração política do Estado ser favorável à concentração de funções e responsabilidades a esse poder e, terceiro fator, pelo apoio popular que experimenta a figura do Chefe do Executivo.

Quanto às divergências entre o neoconstitucionalismo, o hiperpresidencialismo e a democracia representativa, não há uma conclusão se são incompatíveis, se os dois primeiros têm consistência teórica, ou seja, se existem de fato suas ideologias.

Aliás, o neoconstitucionalismo, ante seu caráter transformador, pode ser um substrato teórico para estimular práticas mais participativas na democracia representativa.

Assim, partido do conceito dos institutos supracitados, diante da crise política que vive o país, tornou-se inevitável não cogitar a necessidade de uma reforma política em prol da sociedade, momento qual, que se enfatiza a configuração política brasileira e seus vícios como um dos fatores que mais favorecem ao presidencialismo de coalizão.

\section{Referências}

ABRANCHES, Sergio Henrique Hudson. Presidencialismo de coalizão: o dilema institucional brasileiro. Revista de Ciências Sociais, Rio de Janeiro, vol. 31, n. 1, 1988, pp. 5 a J4 . Disponível em: https://politica3unifesp.files.wordpress.com/2013/01/74783229presidencialismo-de-coalizao-sergio-abranches.pdf. Acesso em: 14 jan. 2020.

ALONSO, Ricardo P. Há futuro para a democracia brasileira? Revista Videre, Dourados, v. 10, n.18, p. 129-141, jul./dez. 2017. Disponível em:

https://ojs.ufgd.edu.br/index.php/videre/article/view/7066/4244. Acesso em: 12 fev. 2020.

ALVES, Fernando Brito. Constituição e participação popular: a construção históricodiscursiva do conteúdo jurídico-político da democracia como Direito Fundamental. Curitiba: Juruá, 2013. 
ARAÚJO, Luiz Alberto David. Curso de direito constitucional. $11^{\mathrm{a}}$ ed. São Paulo: Saraiva, 2007.

BARCELLOS, Ana Paula de. Neoconstitucionalismo, direitos fundamentais e controle das políticas públicas. Revista Diálogo Jurídico, Salvador, Março de 2007. Disponível em: http://www.direitopublico.com.br/pdf_seguro/artigo_controle_pol ticas_p_blicas_.pdf. Acesso em: 31 out. 2016.

BASTOS JR, Ronaldo Carvalho. O desenho constitucional hiperpresidencialista na américa latina. Revista Direitos Humanos e Sociedade, Criciúma, v. 2, n. 1, p. 195-227, 2019. Disponível em: http://periodicos.unesc.net/dirhumanos/article/download/5566/5040. Acesso em: 14 dez. 2019.

BOLONHA, Carlos. RANGEL, Henrique. CORREIA, Flavio. Hiperpresidencialismo na América Latina. Revista da Faculdade de Direito - UFPR, Curitiba, vol. 60, n. 2, maio/ago. 2015, p. 115-140. Disponível em: https://revistas.ufpr.br/direito/article/view/39132/26047. Acesso em: 15 abr. 2020.

BRASIL. TSE. Como funciona o sistema proporcional. Texto redigido por Pedro Luiz Barros Palma Rosa. Disponível em: http://www.tse.jus.br/institucional/escola-judiciariaeleitoral/revistas-da-eje/artigos/revista-eletronica-eje-n.-5-ano-3/como-funciona-o-sistemaproporcional. Acesso em: 05 nov. 2016.

CAMBI, Eduardo. Neoconstitucionalismo e neoprocessualismo: direitos fundamentais, políticas públicas e protagonismo judiciário. 3. ed. Belo Horizonte: D’Plácido, 2020.

CANOTILHO, J.J. Gomes; MOREIRA, Vital. Fundamentos da Constituição. Coimbra: Coimbra, 1991.

CHARLEAUX, João Paulo; IANDOLI, Rafael. Como anda a popularidade dos presidentes dos 10 maiores países da América do Sul. Jornal Nexo, Brasil. 11 de agosto de 2016. Disponível em: https://www.nexojornal.com.br/expresso/2016/08/11/Como-anda-apopularidade-dos-presidentes-dos-10-maiores-pa\%C3\%ADses-da-Am\%C3\%A9rica-do-Sul. Acesso em: 27 out. 2016.

COLOMBIA. Sentencia C-141 de 2010. Disponível em:

$<$ http://www.corteconstitucional.gov.co/relatoria/2010/c-141-10.htm $>$. Acesso em: 31 out. 2015.

COSTA, Valeriano. Multipartidarismo impede concentração de poder político. O Estado de São Paulo, São Paulo, 2012. Disponível em:

http://politica.estadao.com.br/noticias/eleicoes,multipartidarismo-impede-concentracao-depoder-politico-imp-,965159. Acesso em: 27 out. 2016.

DUARTE, A. O pensamento à sombra da ruptura. São Paulo: Paz e Terra, 2000.

EQUADOR. Constitucion De La Republica Del Ecuador. 2008. Disponível em: http://www.oas.org/juridico/pdfs/mesicic4_ecu_const.pdf. Acesso em: 26 out. 2016.

KOSELLECK, R.; RICHTER, M.. "Crisis”. Journal of the History of Ideas, n. 67(2), 2006. 
LANGOSKI, Deisemara Turatti; BRAUN, Helenice A. Dambrós. Novo constitucionalismo latino-americano: o pluralismo jurídico e a perspectiva intercultural dos direitos humanos. In: BAEZ, Narciso Leandro Xavier et al. (coords). Mecanismos de efetividade dos direitos fundamentais. Florianópolis: CONPEDI, 2014. Disponível em: http://www.publicadireito.com.br/artigos/?cod=8d566a338d7758ba. Acesso em: 31 out. 2016.

LAUVAUX, Philippe. Les grandes démocraties contemporaines. Paris: Press Universitaires de France, 1990.

LIMONGI, Fernando; FIGUEIREDO, Argelina. Bases institucionais do presidencialismo de coalizão. Lua Nova, São Paulo, n. 44, p. 81-106, 1998. Disponível em: https://www.scielo.br/scielo.php?script=sci abstract\&pid=S010264451998000200005\&lng=en\&nrm=iso\&tlng=pt. Acesso em: 22 mar. 2016

LÓPEZ, Leandro; CUENCA, María José. Hiperpresidencialismo y calidad democrática en Argentina. In: XI Congreso Nacional y IV Congreso Internacional sobre Democracia (Rosario, 2014), p. 1-18, 2014. Disponível em: http://sedici.unlp.edu.ar/bitstream/handle/10915/45724/Documento_completo.pdf?sequence= 3. Acesso em: 18 mar. 2020.

MAINWARING, Scott. Democracia Presidencialista multipartidária: o caso do Brasil. Lua Nova, São Paulo, n. 28-29, p. 21-74, Abr. 1993. Disponível em: https://www.scielo.br/scielo.php?script=sci_arttext\&pid=S010264451993000100003\&lng=en\&nrm=iso. Acesso em: 27 out. 2016.

NUNES JÚNIOR, Vidal Serrano. A cidadania social na Constituição de 1988: estratégias de positivação e exigibilidade judicial dos direitos sociais. São Paulo: Editora Verbatim, 2009.

PALLARES, Martin. Ecuador's Political Eruption. The New York Times, New York/ Estados Unidos. 1 de Set. 2015. Disponível em:

http://www.nytimes.com/2015/09/02/opinion/ecuadors-politicaleruption.html?action=click\&pgtype $=$ Homepage\&version=Moth-Visible\&module=inside-nytregion\&region=inside-nyt-region\&WT.nav=inside-nyt-region\&_r=0. Acesso em: 27 out. 2016.

PELLENZ, Mayara; BASTIANI, Ana Cristina Bacega de. Pós-Constituição Federal de 1988: a democracia representativa está em crise? Revista Videre, Dourados, v. 07, n. 13, p. 92108, jan./jun. 2015. Disponível em: https://ojs.ufgd.edu.br/index.php/videre/article/view/4806/2612. Acesso em: 12 abr. 2020.

PENFOLD, Michael. La democracia subyugada: el hiperpresidencialismo venezolano. Revista de ciencia política (Santiago), v. 30, n. 1, p. 21-40, 2010. Disponível em: https://scielo.conicyt.cl/scielo.php?script=sci_arttext\&pid=S0718090X2010000100003\&lng=en\&nrm=iso\&tlng=en. Acesso em: 15 abr. 2020.

PERU. Constitucion Politica Del Peru - 1993. Disponível em: http://www.pcm.gob.pe/wpcontent/uploads/2013/09/Constitucion-Pol\%C3\%ADtica-del-Peru-1993.pdf. Acesso em: 26 out. 2016. 
PULIDO, Carlos Libardo Bernal. Direitos fundamentais, juristocracia constitucional e hiperpresidencialismo na América Latina. Revista Jurídica da Presidência, Brasília, v. 17, n. 111, p. 15-34, Fev./Maio 2015. Disponível em:

https://revistajuridica.presidencia.gov.br/index.php/saj/article/view/1105/1091. Acesso em: 10 mar. 2020.

ROITMAN, Janet. Crisis. In: Political Concepts: a critical lexicon. Disponível em: http://www.politicalconcepts.org/issue1/crisis/. Acesso em: 30 abr. 2020.

SCHIMITT, Carl. The Concept of Political. Trad. George Schwab. Chicago: Chicago University Press, 2007.

SILVA, José Afonso. Curso de direito constitucional positivo. 22. ed. São Paulo: Malheiros Editores, 2007. 